\title{
PENGARUH PEMBERIAN KOMPRES AIR HANGAT TERHADAP PENURUNAN INTENSITAS NYERI DYSMENORRHEA PADA REMAJA PUTRI DI SMA NEGERI 10 KOTA BENGKULU
}

\author{
Vellyza Colin, Buyung Keraman, Dwi Rolita \\ Email: vellyzacolin7@gmail.com
}

\begin{abstract}
ABSTRAK
Masa pubertas yaitu bagian dari proses perkembangan dengan adanya kematangan organ seksual dan kemampuan bereproduksi, yang ditandai dengan terjadinya menstruasi pertama (menarche). Menstruasi adalah perubahan secara fisiologis pada perempuan. Dysmenorrhea adalah nyeri perut yang berasal dari kram rahim dan terjadi selama menstruasi. Beberapa perempuan mengalami sakit dan kram saat haid berlangsung. Rasa sakit biasanya terjadi di perut bagian bawah. Secara umum penanganan nyeri dismenore terbagi dalam dua kategori yaitu pendekatan farmakologis dan non farmakologis. Penelitian ini bertujuan untuk mengetahui pengaruh pemberian kompres air hangat terhadap penurunan intensitas nyeri dysmenorrhea pada remaja putri di SMA Negeri 10 Kota Bengkulu. Rancangan penelitian ini adalah Pra-Eksperiment dengan desain OneGroup Pre-Post Test Design, menggunakan Accidental sampling dengan jumlah sampel 30 responden. Alat yang digunakan adalah kuesioner lembar karakteristik responden dan Numeric Rating Scale (NRS) untuk mengetahui intensitas nyeri. Analisis data menggunakan wilcoxon signed-rank test. Hasil penelitian ini terdapat pengaruh pemberian kompres air hangat terhadap penurunan intensitas nyeri dysmenorrhea pada remaja putri di SMA Negeri 10 Kota Bengkulu diperoleh nilai $Z=-4.801$ dengan $p-$ value $=0,000<0,05$ yang berarti signifikan. Diharapkan bagi sekolah dan siswi melakukan kompres air hangat sebagai salah satu alternatif terapi non farmakologis untuk mengurangi nyeri dysmenorrhea.
\end{abstract}

Kata Kunci: Kompres Air Hangat, Nyeri Dysmenorrhea, Remaja Putri

\section{The Effect of Providing Warm Water Compress to Decreasing Dysmenorrhea Pain Intensity on Adolescent Girls at SMA Negeri 10 Bengkulu City}

\begin{abstract}
Puberty is part of the development process with the maturation of the sexual organs and the ability to reproduce, which is marked by the occurrence of the first menstruation (menarche). Menstruation is a physiological change in women. Dysmenorrhea is abdominal pain that comes from uterine cramps and occurs during menstruation. Some women experience pain and cramps during menstruation. Pain usually occurs in the lower abdomen. In general, dysmenorrhea pain management is divided into two categories, namely pharmacological and non-pharmacological approaches. The aims of this study was to determine The Effect of Providing Warm Water Compress to Decreasing Dysmenorrhea Pain Intensity on Adolescent Girls at SMA Negeri 10 Bengkulu City. This study uses Pre-Experiment with One-Group Pre-Post Test Design, sampling technique in this study uses accidental sampling with total of 30
\end{abstract}


respondents. Instrumet in this study was questionnaire of respondent characteristic sheet and Numeric Rating Scale (NRS) to determine the intensity of pain. Data analysis using Wilcoxon signed-rank test. The results of this study showed there is effect of Providing Warm Water Compress to Decreasing Dysmenorrhea Pain Intensity on Adolescent Girls at SMA Negeri 10 Bengkulu City obtained a value of $\mathrm{Z}=-4,801$ with $\mathrm{p}$-value $=0,000<0.05$, which means significant. It is expected for school and students to compress warm water as an alternative nonpharmacological therapy to reduce the pain of dysmenorrhea.

Keywords: Warm Water Compress, Dysmenorrhea Pain, Adolescent Girls

\section{Pendahuluan}

$\begin{array}{clr}\text { Masa } & \text { remaja adalah masa } \\ \text { peralihan dari anak-anak } & \text { ke }\end{array}$ dewasa.Definisi remaja sendiri dapat ditinjau dari tiga sudut pandang yaitu secara kronologis, remaja adalah individu yang berusia antara 11-12 tahun sampai 20-21 tahun.Secara fisik, remaja ditandai dengan adanya perubahan ukuran dan penampilan fisik dan adanya kemampuan bereproduksi, dan secara psikologis, remaja mengalami perubahan pada kognitif, mental, sosial dan moral (Kusmiran, 2012). Periode masa remaja ini sering disebut masa pubertas yaitu bagian dari proses perkembangan dengan adanya kematangan organ seksual dan kemampuan bereproduksi, yang ditandai dengan terjadinya menstruasi pertama (menarche) (Widyastuti, 2009).

Menurut Kusmiran

menstruasi adalah perubahan secara fisiologis pada perempuan. Menstruasi adalah perdarahan yang teratur dari uterus sebagai tanda bahwa organ kandungan telah berfungsi matang. Secara umum, remaja mengalami menarche adalah usia 12 sampai dengan 16 tahun, dengan siklus menstruasi normal terjadi setiap 22-35 hari, dengan lamanya menstruasi 2-7 hari.

Dysmenorrhea adalah nyeri perut yang berasal dari kram rahim dan terjadi selama menstruasi (Nugroho\&
Utama, 2014). Beberapa perempuan mengalami sakit dan kram saat haid berlangsung. Rasa sakit biasanya terjadi di perut bagian bawah.Ada dua jenis dysmenorrhea. Bila rasa sakit tidak disertai adanya riwayat infeksi pada panggul atau keadaan panggul normal, dinamakan dysmenorrhea primer. Gejalanya ditandai dengan ingin muntah, mual sakit kepala, nyeri punggung dan pusing. Penyebab yang pasti belum diketahui, para ahli menduga rasa sakit ini disebabkan kontraksi otot dinding rahim. Dari kasus haid yang dialami perempuan, $75 \%$ kasus merupakan dysmenorrhea primer (Sibagariang, 2016).

Menurut beberapa laporan Internasional prevalensi dismenoreasangattinggi dan setidak-nya $50 \%$ remaja putri mengalami dismenorea sepanjang tahun reproduktif. Hasil studi terbaru menunjukkan bahwa hampir $10 \%$ remaja yang dis-menorea mengalami absen sekolah danabsen kerja 1-3 hari per bulan atau kemampuan remaja dalam melakukan tugas sehari-hari akibat nyeri hebat (Umi. dkk, 2010). Angka kejadian nyeri haid di dunia sangat besar, rata-rata lebih dari 50\% perempuan disetiap Negara mengalami Dismenorea baik primer maupun sekunder (Novia\&Puspitasari, 2009). Di Amerika Serikat, insiden dismenorea pada remaja putri dilaporkan sekitar 92\%. Puncak insiden 
dismenorea primer terjadi pada akhir masa remaja (ado-lescence) dan di awal usia 20-an (Anurogo, 2011). Di Indonesia perempuan yang pernah mengalami dismenorea sebanyak 90\% (Anurogo, 2011).

Secara umum penanganan nyeri dismenore terbagi dalam dua kategori yaitu pendekatan far-makologis dan non farmakologis. Secara farmakologis nyeri dapat ditangani dengan terapi analgesik yang merupakan metode paling umum digunakan untuk menghilangkan nyeri. Walaupun analgesik dapat menghilangkan nyeri dengan efektif, namun penggunaan analgesik akan berdampak ketagihan dan akan memberikan efek samping obat yang berbahaya bagi pasien. Secara non farmakologik antara lain kompres hangat, teknik relaksasi seperti nafas dalam dan yoga (Potter \& Perry, 2005).

Kompres hangat dengan menggunakan buli-buli panas yang mana secara konduksi dimana terjadi pemindahan panas dari buli-buli ke dalam tubuh sehingga akan menyebabkan pelebaran pembuluh darah sirkulasi menjadi lancar dan akan menjadi ketegangan otot, sesudah otot miometrium rilek, rasa nyeri yang dirasakan berangsur-angsur berkurang bahkan hilang (Merdianita, 2013).

Berdasarkan wawancara yang dilakukan pada bulan November 2018, terhadap 15 orang siswi SMA Negeri 10 Kota Bengkulu, didapatkan 12 orang mengalami dysmenorrhea, 3 orang tidak mengalami dysmenorrhea, 7 orang mengatakan nyeri skala ringan, 4 orang nyeri skala sedang, 1 orang nyeri skala berat. Pada 7 orang mahasiswi merasakan dys-menorrhea selama 2 hari saat menstruasi, 4 orang merasakan dysmenorrhea pada hari pertama menstruasi, dan 1 orang mahasiswi merasakan dysmenorrhea pada 2-4 jam pada hari pertama menstruasi. Keluhan yang paling sering dirasakan 3 orang mengatakan pusing dan mual, 7 orang mengatakan nyeri perut sampai punggung bawah, 2 orang mengatakan sakit pada payudara, dan terjadi kelemahan pada ekstermitas bawah. Mereka me-ngatakan jika mengalami dy-smenorrhea sekolah terganggu atau aktivitas lainnya terganggu karena harus beristirahat. Siswi yang di wawancara juga mengatakan belum pernah mencoba mengompres hangat di area punggung bawah saat mengalami nyeri dysmenorrhea. Dengan adanya landasan di atas, maka peneliti ingin mengetahui bagaimana pengaruh pemberian kompres air hangat terhadap intensitas nyeri dysmenorrhea pada siswi SMA Negeri 10 Kota Bengkulu. Rumusan masalah dalam penelitian ini adalah apakah ada pengaruh pemberian kompres air hangat terhadap penurunan intensitas nyeri dysmenorrhea pada remaja putri di SMA Negeri 10 Kota Bengkulu.

Tujuan penelitian ini adalah diketahuinya pengaruh pengaruh pemberian kompres air hangat terhadap penurunan intensitas nyeri dysmenorrhea pada remaja putri di SMA Negeri 10 Kota Bengkulu, diketahuinya intensitas nyeri dysmenorrhea sebelum dan sesudah dilakukan kompres air hangat.

\section{Metode Penelitian}

Penelitian ini dilakukan di SMA Negeri 10 Kota Bengkulu. Penelitian ini dilakukan pada tanggal 06 Juni - 24 Juli 2019. Rancangan penelitian ini adalah Pra-Eksperiment dengan desain One-Group Pre-Post Test Design. Penelitian ini memberikan inter-vensi kepada responden yang akan dilakukan tindakan perlakuan dan membandingkan sebelum dan sesudah dilakukan intervensi. Populasi dalam 
penelitian ini adalah siswi SMA Negeri 10 Kota Bengkulu kelas XI yang mengalami dysmenorrhea sebanyak 83 orang. Dalam penelitian ini sampel yang diambil menggunakan Accidental sampling dimana metode ini dilakukan dengan cara mengambil kasus atau responden yang kebetulan ada atau tersedia di suatu tempat sesuai dengan karakteristik penelitian pada saat dilakukan penelitian. Pengumpulan data dilakukan dengan cara wawancara pada siswi SMA Negeri 10 Kota Bengkulu dan observasi yang dibantu dengan instrumen dalam bentuk kuesioner/lembar per-tanyaan, kemudian melakukan tindakan kompres hangat guna mengetahui apakah terjadi pe-nurunan rasa nyeri yang dirasakan pasien dan selanjutnya melakukan pengukuran intensitas nyeri setelah dilakukan tindakan kompres hangat. Teknik analisa data menggunakan uji normalitas data dengan Shapiro Wilk, univariat dan bivariat menggunakanuji Wilcoxon Sign Rank Test.

\section{Hasil Penelitian dan pembahasan \\ 1. Analisis Univariat}

Analisis ini dilakukan untuk mendapatkan gambaran masingmasing variabel yang diteliti, baik variabel independen maupun dependen

Tabel 1.

Distribusi Frekuensi Intensitas Nyeri Dysmenorrhea Responden Sebelum Pemberian Kompres Air Hangat di SMA Negeri 10 Kota Bengkulu.

\begin{tabular}{cccc}
\hline Kategori nyeri & $\begin{array}{c}\text { Skala } \\
\text { Nyeri }\end{array}$ & $\begin{array}{c}\text { Frekuensi } \\
(\mathbf{n})\end{array}$ & $\begin{array}{c}\text { Persentase } \\
(\mathbf{\%})\end{array}$ \\
\hline Nyeri ringan & $1-3$ & 3 & 10,0 \\
Nyeri sedang & $4-6$ & 19 & 63,3 \\
Nyeri berat & $7-9$ & 8 & 26,7 \\
\hline Total & & $\mathbf{3 0}$ & $\mathbf{1 0 0}$ \\
\hline \multicolumn{2}{c}{ Dari tabel di atas dapat } & nyeri ringan, 19 orang (63,3\%) \\
diketahui tingkat intensitas & mengalami nyeri sedang dan 8 \\
nyeri dysmenorrhea sebelum & orang (26,7\%) mengalami nyeri \\
dilakukan kompres air hangat & berat.
\end{tabular}

yaitu 3 orang (10\%) mengalami 
Tabel 2.

Distribusi Frekuensi Intensitas Nyeri Dysmenorrhea Responden Sesudah Pemberian Kompres Air Hangat di SMA Negeri 10

Kota Bengkulu.

\begin{tabular}{cccc}
\hline Kategori nyeri & Skala nyeri & $\begin{array}{c}\text { Frekuensi } \\
\text { (n) }\end{array}$ & $\begin{array}{c}\text { Persentase } \\
(\mathbf{\%})\end{array}$ \\
\hline Tidak nyeri & 0 & 12 & 40 \\
Nyeri ringan & $1-3$ & 12 & 40 \\
Nyeri sedang & $4-6$ & 6 & 20 \\
\hline Total & & $\mathbf{3 0}$ & $\mathbf{1 0 0}$ \\
\hline
\end{tabular}

Dari tabel di atas dapat diketahui tingkat intensitas nyeri dysmenorrhea sesudah dilakukan kompres air hangat yaitu 12 orang $(40 \%)$ tidak nyeri, 12 orang $(40 \%)$ mengalami nyeri ringan dan 6 orang (20\%) mengalami nyeri sedang.

\section{Uji Normalitas Data}

Hasil uji normalitas data menggunakan uji Shapiro wilk diperlihatkan pada tabel sebagai berikut:

Tabel 3 .

Hasil Uji Normalitas Data

\begin{tabular}{cccc}
\hline $\begin{array}{c}\text { Intensitas nyeri } \\
\text { dysmenorrheal }\end{array}$ & Statistik & Df & Sign \\
\hline $\begin{array}{c}\text { Dysmenorrhea Sebelum } \\
\text { Kompres Hangat } \\
\begin{array}{c}\text { Dysmenorrhea Sesudah } \\
\text { Kompres Hangat }\end{array}\end{array}$ & .922 & 30 & .031 \\
\hline
\end{tabular}

Hasil uji normalitas data dengan uji Shapiro-Wilk dapat diketahui:

a. $\mathrm{P}$-value $=0,031<0,05$ untuk data dysmenorrhea sebelum kompres hangat, berarti tidak normal.

b. P-value $=0,000<0,05$ untuk data dysmenorrhea sesudah kompres hangat, berarti tidak normal.

Dimana dikatakan berdistribusi normal apabila $p$ value $>0,05$.

Karena dua kelompok data tersebut tidak normal maka digunakan uji Wilcoxon Sign Rank.

\section{Analisis Bivariat}

Analisis bivariat dilakukan untuk mengetahui pengaruh pemberian kompres air hangat terhadap penurunan intensitas nyeri dysmenorrhea pada remaja putri di SMA Negeri 10 Kota Bengkulu menggunakan uji Wilcoxon Signed Ranks Test. Hasil analisa uji wilcoxon pada penelitian ini disajikan dalam tabel sebagai berikut: 
Tabel 4.

Analisa Pengaruh Pemberian Kompres Air Hangat Terhadap Penurunan Intensitas Nyeri dysmenorrhea pada Remaja Putri di SMA

Negeri 10 Kota Bengkulu

\begin{tabular}{|c|c|c|c|c|c|c|}
\hline Variabel & Rank & $\mathbf{N}$ & $\begin{array}{l}\text { Mean } \\
\text { Rank }\end{array}$ & $\begin{array}{l}\text { Sum of } \\
\text { Ranks }\end{array}$ & $\mathbf{Z}$ & $\begin{array}{c}\text { P- } \\
\text { Value }\end{array}$ \\
\hline $\begin{array}{c}\text { Dysmenorrhea } \\
\text { Sesudah Kompres }\end{array}$ & $\begin{array}{l}\text { Negative } \\
\text { Ranks }\end{array}$ & 30 & 15.50 & 465.00 & & \\
\hline $\begin{array}{c}\text { Hangat - } \\
\text { Dysmenorrhea }\end{array}$ & $\begin{array}{l}\text { Positive } \\
\text { Ranks }\end{array}$ & 0 & .00 & .00 & -4.801 & 0,000 \\
\hline Sebelum Kompres & Ties & 0 & & & & \\
\hline Hangat & Total & 30 & & & & \\
\hline
\end{tabular}

Berdasarkan tabel diatas dapat diketahui bahwa dari 30 responden skala nyeri posttest mengalami penurunan dari pada skala nyeri pretest. Sedangkan untuk skala nyeri posttest pemberian kompres air hangat tidak ada skala nyeri yang meningkat. Dan setelah diberikan kompres air hangat tidak ada skala nyeri yang sama atau tidak mengalami penurunan. Berdasarkan hasil uji wilcoxon dengan menggunakan SPSS diperoleh nilai $\mathrm{Z}=$ -4.801 dengan $p$-value $=0,000<0,05$ yang berarti signifikan, maka hasil penelitian ini adalah $\mathrm{Ho}$ ditolak dan $\mathrm{Ha}$ diterima. Sehingga dapat diartikan "Terdapat pengaruh pemberian kompres air hangat terhadap penurunan intensitas nyeri dysmenorrhea pada remaja putri di SMA Negeri 10 Kota Bengkulu.

\section{Pembahasan}

Penelitian ini membuktikan bahwa ada perbedaan antara skala nyeri menstruasi (dysmenorrhea) sebelum pemberian terapi kompres hangat dan sesudah pemberian terapi kompres hangat. Dari hasil analisis data yang diperoleh pada tabel 5. Hal ini terbukti pada hasil perlakuan yang telah dilaksanakan oleh peneliti pada 30 responden di SMA Negeri 10 Kota Bengkulu pada awal sebelum diberikan (tabel 4). Sesudah pemberian kompres hangat, ternyata mampu menurun-kan nyeri menstruasi (dysme-norrhea). Pada hasil penelitian ditemukan terjadi penurunan nilai rata-rata skala nyeri sebelum dan sesudah dilakukan terapi kompres hangat dan setelah dilakukanujiWilxocon-test

menggunakan pro-gram SPSS didapatkan hasil Asymp. Sig. (2tailed) $0.00<\alpha=0,05$. Hal ini menunjukkan bahwa terapi kompres hangat berdampak positif dalam menurunkan nyeri dysmenorrhea sehingga menjawab yaitu Ha diterima. Hasil penelitian ini didukung oleh teori Lowdermilk, dkk (2013) dimana nyeri dysmenorrhea dapat berkurang dengan terapi non-farmakologi berupa kompres hangat yaitu memberikan rasa aman pada responden dengan menggunakan cairan atau alat yang menimbulkan hangat pada bagian tubuh yang memerlukan. Hal ini berakibat terjadi pemindahan panas keperut sehingga perut yang dikompres menjadi hangat, terjadi pelebaran pembuluh darah dibagian yang mengalami nyeri serta me-ningkatnya aliran darah pada daerah tersebut sehingga nyeri dismenore yang dirasakan akan berkurang atau hilang. Secara non farmakologis kompres hangat sangat bermanfaat dalam penurunan nyeri 
dismenore dimana terjadinya relaksasi otot serta mengurangi iskemia uterus sehingga nyeri dapat berkurang atau hilang. Hal ini dapat terlihat pada hasil penelitian yang menunjukkan bahwa sebelum dilakukan perlakuan terapi kompres hangat banyak siswi yang berada pada skala nyeri sedang dan sesudah dilakukan terapi kompres hangat terjadi penurunan yang banyak berada pada skala 0 (tidak nyeri).Kompres hangat sangat efektif dilakukan untuk mengurangi nyeri dismenore karena tidak me-merlukan biaya yang banyak, waktu yang lama, dan kerja fisik yang berat tetapi harus tetap hati-hati karena air yang terlalu panas dapat mengakibatkan iritasi pada kulit. Penelitian ini senada dengan penelitianyang telah dilakukan oleh Ayu (2010) diperoleh penurunan ratarata nyeri kelompok kompres hangat sebesar 2 derajat skala VAS dengan nilai $\mathrm{p}$ value $0,001(<0,005)$. Karena $\mathrm{P}$ value $<0,05$ sehingga $\mathrm{H} 0$ ditolak hal ini menunjukkan ada pengaruh yang signifikan sebelum dan sesudah dilakukan kompres hangat.Menurut Potter dan Perry, (2006), mekanisme terjadinya penurunan nyeri akibat dilakukan kompres hangat karena ketika panas diterima reseptor, impuls akan diteruskan menuju hipotalamus posterior akan terjadi reaksi reflek penghambatan simpatis yang akan membuat pembuluh darah berdilatasi sehingga membantu meningkatkan aliran darah ke bagian perut bawah yang mengalami nyeri/dismenorea, panas meredakan nyeri dengan menyingkirkan produk-produk in-flamasi seperti bradikinin, histamin dan prostaglandin yang me-nimbulkan rasa nyeri lokal.

Penelitian yang dilakukan Bonde (2014) tentang Pengaruh kompres panas terhadap penurunan derajat nyeri haid pada siswi SMA dan SMK Yadika
Kopandakan II dengan analisis uji statistik uji Wilcoxon, hasil dari nilai pmenunjukkan bahwa ada hubungan yang bermakna antara kompres panas dengan penurunan derajat nyeri haid $(p=0,00)$. Berdasarkan hasil penelitian ini dapat disimpulkan bahwa kompres panas berpengaruh terhadap penurunan derajat nyeri haid pada siswi SMA dan SMK YadikaKopandakan II. Begitu pula menurut Nida (2016), berdasarkan hasil uji statistik Wilcoxon SignedRanks Test pengaruh kompres hangat terhadap penurunan nyeri haid pada siswi kelas XI di SMK Muhammadiyah Watukelir didapatkan nilai signifikasi $(p) 0,00$ yang berarti bahwa nilai $p(0,00)$ kurang dari 0,05 ; sehingga dapat disimpulkan bahwa ada pengaruh pemberian kompres hangat ter-hadap penurunan nyeri dismenore. Hal ini dapat dijelaskan dengan teori yang dikemukakan oleh Perry \& Potter (2005) pengompresan yang dilakukan dengan mempergunakan buli-buli panas yang di bungkus kain yaitu secara konduksi dimana terjadi pemindahan panas dari buli-buli ke dalam tubuh sehingga akan menyebabkan pelebaran pembuluh darah dan akan terjadi penurunan ketegangan otot sehingga nyeri haid yang dirasakan akan berkurang atau hilang, panas dapat menyebabkan dilatasi pembuluh darah yang mengakibatkan peningkatan sirkulasi darah. Berdasarkan fakta dan teori diatas dapat disimpulkan, bahwa terapi kompres hangat sangat bermanfaat dalam penurunan skala nyeri menstruasi (dismenore) dimana terjadinya relaksasi otot serta mengurangi iskemia uterus sehingga nyeri dapat berkurang atau hilang dan remaja putri mulai membiasakan diri pada saat nyeri menstruasi datang akan melakukan kompres hangat pada perlakuan yang sama. 


\section{Simpulan}

Sebelum diberikan intervensi kompres air hangat rata-rata intensitas nyeri responden dalam kategori nyeri sedang sebanyak 19 orang $(63,3 \%)$, Setelah diberikan intervensi kompres air hangat sebagian besar 12 orang (40\%) tidak nyeri, 12 orang $(40 \%)$ mengalami nyeri ringan, Ada pengaruh pemberian kompres air hangat terhadap penurunan intensitas nyeri dysmenorrhea pada remaja putri di SMA Negeri 10 Kota Bengkulu.

\section{Daftar Pustaka}

Anurogo, D \&Wulandari, A. 2011.Cara Jitu Mengatasi Nyeri Haid. Yogyakarta: ANDI.

Ayu. 2010. Pengaruh Kompres Hangat Terhadap Dismenorea Primer Pada Mahasiswi semester VIII S1 Keperawatandi Universitas Muhammadiyah Semarang 2 (5). 1-7. Diakses pada tanggal 28 November 2018,

Bonde, Fitrah, M.P., FransiskaLintong, Maya Moningka. 2014. Pengaruh Kompres Panas terhadap Penurunan Derajat Nyeri Haid pada Siswi SMA dan SMK YadikaKopandakan II. Jurnal Fisika FakultasKedokteran Universitas Sam Ratulangi Manado. 3 (2)1-5. Diakses pada tanggal 5 Desember 2018,.

Kusmiran, E. 2012.Kesehatan Reproduksi Remaja Dan Wanita. Jakarta: SalembaMedika

Lowdermilk., Perry., Cashion. 2013. KeperawatanMaternitas. Jakarta: PT. Salemba Emban Patria.

Merdianita, Vonny. dkk. 2013. Efektivitas Kompres Hangat Dalam Menurunkan intensitas
Nyeri Dysmenorrhoea Pada Mahasiswa STIKES RS Baptis Kediri.Jurnal STIKES RS Baptis Kediri 6 (1).1-10. Diakses pada tanggal 5 Desember 2018, dari

Nida, R. M., \& Sari, D. S. 2016. Pengaruh Pemberian Kompres Hangat Terhadap Penurunan Nyeri Dismenore Pada Siswi Kelas Xi SmkMuhammadiyahWatukelirSu koharjo (The Influence Of Warm Compress Decrease In Dismenorhea Eleventh Grade Students Of SmkMuhammadiyahWatukelirSu koharjo). Jurnal Kebidanan Dan Kesehatan Tradisional, 1(2). 103-109. Diakses pada tanggal 02 Januari 2019.

NoviaI,\&Puspitasari N. 2008. Faktor Risiko yang Mempengaruhi Kejadian Dismenore Primer.Fakultas Kesehatan Masyarakat Universitas Airlangga. 1(3). 96-103. Diakses pada tanggal 05 Desember 2018.

Nugroho.T\& Utama. B. I. 2014. Masalah Kesehatan Reproduksi Wanita. Yogyakarta: NuhaMedika.

Potter \& Perry. 2005. Buku AjarFundamentalkeperawatan: Konsep, Proses dan Praktik. Volume 1.Edisi 4. Jakarta: Penerbit Buku Kedokteran EGC. .2006.Buku Ajar Fundamental Keperawatan: Konsep, Proses dan Praktik. Volume 2.Edisi 4. Jakarta: Penerbit Buku Kedokteran EGC. 
Sibagariang, E. E. 2016. Kesehatan Reproduksi Wanita. Edisi Revisi. Jakarta: CV. Trans Info Media

Umi, dkk. 2010. "Gambaran Pengetahuan Tentang
Dismenorea Dan Penanganan Dismenorea".Semarang program sarjana".

Widyastuti, Y., dkk. 2009. Kesehatan Reproduksi. Yogyakarta: 